\title{
Hypercarnivorous teeth and healed injuries to Canis chihliensis from early Pleistocene Nihewan beds, China, support social hunting for ancestral wolves
}

\author{
Haowen Tong ${ }^{\text {Equal first author, 1, 2,3 }}$, Xi Chen ${ }^{4}$, Bei Zhang ${ }^{1,2,3}$, Bruce Rothschild ${ }^{5}$, Stuart White ${ }^{6}$, Mairin Balisi ${ }^{7}$, Xiaoming \\ Wang ${ }^{\text {Corresp. Equal first author, 1, } 7}$ \\ ${ }^{1}$ Key Laboratory of Vertebrate Evolution and Human Origins of Chinese Academy of Sciences, Institute of Vertebrate Paleontology and Paleoanthropology, \\ Chinese Academy of Sciences, Beijing, China \\ 2 CAS Center for Excellence in Life and Paleoenvironment, Beijing, China \\ 3 University of Chinese Academy of Sciences, Beijing, China \\ 4 Nanjing Normal University, Nanjing, Jiangsu, China \\ 5 Department of Vertebrate Paleontology, Carnegie Museum of Natural History, Pittsburgh, Pennsylvania, United States \\ ${ }^{6}$ School of Dentistry, University of California, Los Angeles, Los Angeles, CA, United States \\ 7 Natural History Museum of Los Angeles County, Los Angeles, CA, United States \\ Corresponding Author: Xiaoming Wang \\ Email address: xwang@nhm.org
}

Collaborative hunting by complex social groups is a hallmark of large dogs (Mammalia: Carnivora: Canidae), whose teeth also tend to be hypercarnivorous, specialized toward increased cutting edges for meat consumption and robust p4-m1 complex for cracking bone. The deep history of canid pack hunting is, however, obscure because behavioral evidence is rarely preserved in fossils. Dated to the early Pleistocene ( 1.2 Ma), Canis chihliensis from the Nihewan Basin of northern China is one of the earliest canines to feature a large body size and hypercarnivorous dentition. We present the first known record of dental infection in C. chihliensis, likely inflicted by processing hard food, such as bone. Another individual also suffered a displaced fracture of its tibia and, despite such an incapacitating injury, survived the trauma to heal. The long period required for healing the compound fracture is consistent with social hunting and family care (food-sharing) although alternative explanations exist. Comparison with abundant paleopathological records of the putatively pack-hunting late Pleistocene dire wolf, Canis dirus, at the Rancho La Brea asphalt seeps in southern California, U.S.A., suggests similarity in feeding behavior and sociality between Chinese and American Canis across space and time. Pack hunting in Canis may be traced back to the early Pleistocene, well before the appearance of modern wolves, but additional evidence is needed for confirmation. 
1 Hypercarnivorous teeth and healed injuries to Canis

2 chihliensis from early Pleistocene Nihewan beds,

3 China, support social hunting for ancestral wolves

4

5

6

7

Hao-Wen Tong ${ }^{1,2,3^{*}}$, Xi Chen ${ }^{4}$, Bei Zhang ${ }^{1,2,3}$, Bruce Rothschild ${ }^{5}$, Stuart C. White ${ }^{6}$, Mairin Balisi $^{7}$, and Xiaoming Wang ${ }^{1,7, *}$

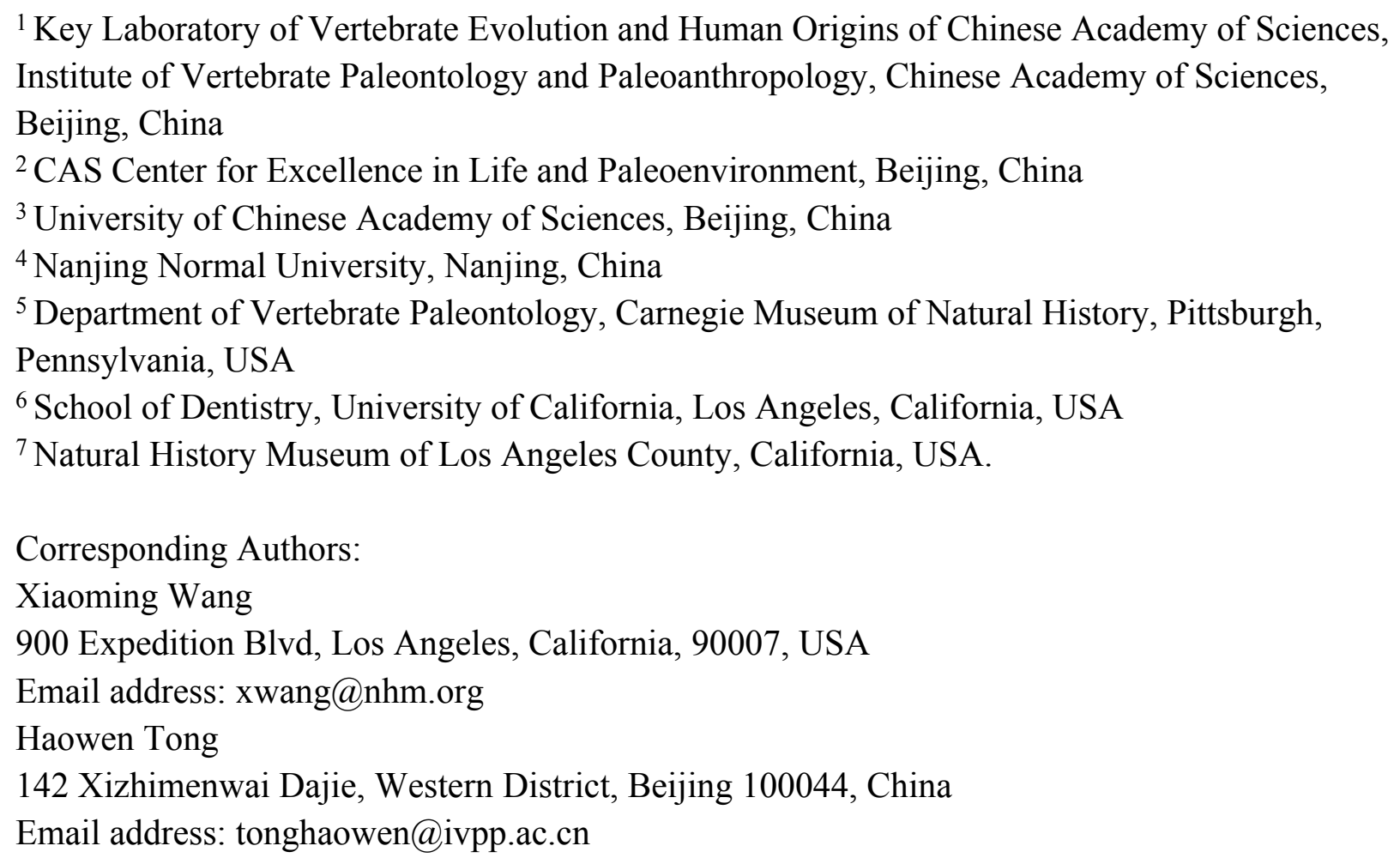
Institute of Vertebrate Paleontology and Paleoanthropology, Chinese Academy of Sciences, Beijing, China

${ }^{2}$ CAS Center for Excellence in Life and Paleoenvironment, Beijing, China

${ }^{3}$ University of Chinese Academy of Sciences, Beijing, China

${ }^{4}$ Nanjing Normal University, Nanjing, China

${ }^{5}$ Department of Vertebrate Paleontology, Carnegie Museum of Natural History, Pittsburgh, Pennsylvania, USA

${ }^{6}$ School of Dentistry, University of California, Los Angeles, California, USA

${ }^{7}$ Natural History Museum of Los Angeles County, California, USA.

Corresponding Authors:

Xiaoming Wang

900 Expedition Blvd, Los Angeles, California, 90007, USA

Email address: xwang@nhm.org

Haowen Tong

142 Xizhimenwai Dajie, Western District, Beijing 100044, China

Email address: tonghaowen@ivpp.ac.cn

\section{Abstract}

Collaborative hunting by complex social groups is a hallmark of large dogs (Mammalia:

Carnivora: Canidae), whose teeth also tend to be hypercarnivorous, specialized toward increased cutting edges for meat consumption and robust $\mathrm{p} 4-\mathrm{m} 1$ complex for cracking bone. The deep history of canid pack hunting is, however, obscure because behavioral evidence is rarely preserved in fossils. Dated to the early Pleistocene ( 1.2 Ma), Canis chihliensis from the Nihewan Basin of northern China is one of the earliest canines to feature a large body size and hypercarnivorous dentition. We present the first known record of dental infection in $C$. chihliensis, likely inflicted by processing hard food, such as bone. Another individual also suffered a displaced fracture of its tibia and, despite such an incapacitating injury, survived the 
37 trauma to heal. The long period required for healing the compound fracture is consistent with

social hunting and family care (food-sharing) although alternative explanations exist.

Comparison with abundant paleopathological records of the putatively pack-hunting late Pleistocene dire wolf, Canis dirus, at the Rancho La Brea asphalt seeps in southern California, U.S.A., suggests similarity in feeding behavior and sociality between Chinese and American Canis across space and time. Pack hunting in Canis may be traced back to the early Pleistocene, well before the appearance of modern wolves, but additional evidence is needed for confirmation.

\section{Introduction}

Large, hypercarnivorous dogs (family Canidae) — such as gray wolves (Canis lupus), African hunting dogs (Lycaon pictus), and Asian dholes (Cuon alpinus) - are known to be highly social because of their need for collaborative hunting (Van Valkenburgh 1991). In all three species, energetic requirements necessitate that they pursue prey species that are larger than themselves (Carbone et al. 1999). But, unlike their felid (cat family) counterparts, canids lack retractile claws and are usually unable to bring down their prey single-handedly (Wang et al. 2008), making collaborative (pack) hunting a useful compensatory strategy. Despite the importance of pack hunting as a key biological indicator for social interactions, trophic relationship, and diets, however, fossil records rarely preserve direct information on behavior.

Discovery of an injured and healed skeleton and jaws of a large ancestral wolf, Canis chihliensis, from the early Pleistocene hominin site of Nihewan Basin, northern China, is of interest in inferring their social behavior. Evidence of healing raises the possibility that individuals survived incapacitating injuries by sharing food with family members (Palmqvist et al. 1999), a question to be explored in this paper.

\section{Materials \& Methods}

The methods employed in this study include morphological observations, CT scanning, and Xray examination. CT slicing intervals followed that of Rothschild et al. (1994). The osteological terms are from Mescher (2018). The stages of fracture healing follow Edge-Hughes \& Nicholson (2007). Age determination follows Sumner-Smith (1966) for epiphyseal fusion and Gipson et al. (2000) for tooth wear. Body-mass estimates were calculated using regressions on canid femur shaft diameter by Anyonge \& Roman (2006) and m1 length by Van Valkenburgh (1990). Permission for excavation was granted by the State Administration of Cultural Heritage with a permit number of 2018-090.

Institution and Locality Abbreviations. HPICR, Hebei Province Institute of Cultural Relics; IVPP, Institute of Vertebrate Paleontology and Paleoanthropology; MNHN, 
74 Muséum national d'Histoire naturelle; NM, Nihewan Museum; NNNRM, Nihewan National

75 Nature Reserve Management; SSMZ, Shanshenmiaozui; TNHM, Tianjin Natural History

76 Museum; V, Prefix in the catalog numbers for vertebrate fossils in IVPP.

77 Morphological Abbreviations: DAP: anteroposterior diameter; DT: transverse diameter; MC: 78 medullar cavity; NF: nutrient foramen.

Locality and Fauna. The present large sample of early Pleistocene wolf, Canis chihliensis, comprises more than 200 specimens including excellently preserved pathological conditions. A left dentary (IVPP V17755.11), a right dentary (IVPP V17755.12), and a right tibia (IVPP V18139.20) of Canis chihliensis are all from the Shanshenmiaozui (SSMZ) Site in Nihewan Basin. C. chihliensis from SSMZ is dominated by older individuals as inferred from wear on teeth (Chen 2018; Chen \& Tong 2015). The SSMZ locality (40¹3'08'N, $\left.114^{\circ} 39^{\prime} 54^{\prime \prime E}\right)$ lies at the southern bank of the Sangganhe River, and at the edge of the Haojiatai fluviolacustrine platform in Yangyuan County, Hebei Province (Fig. S1). The fossiliferous layer was dated to ca. 1.2 Ma by magnetostratigraphy and associated fauna (Liu et al. 2016; Tong et al. 2011).

Canids are the most abundant carnivorans in the Early Pleistocene Nihewan Fauna (Qiu 2000; Teilhard de Chardin \& Piveteau 1930), as also confirmed by our recent excavations at SSMZ (Fig. S2). The dominant taxon of the canid guild in the SSMZ Fauna is Canis chihliensis (Tong et al. 2011; Tong et al. 2012). The mammalian fauna associated with $C$. chihliensis at the SSMZ site are as follows: Lepus sp., Ochotona sp., Pantherinae gen. et sp. indet., Pachycrocuta sp., Mammuthus trogontherii, Coelodonta nihowanensis, Elasmotherium peii, Proboscidipparion sp., Equus sanmeniensis, Sus sp., Eucladoceros boulei, Spirocerus wongi, Bison palaeosinensis, and Gazella sinensis. Our fieldwork between 2015-2018 recovered additional taxa, e.g. Alactaga sp. (represented by metacarpal), Acinonyx sp. (radius), Panthera sp. (partial mandible and manus bones), Lynx sp. (partial mandible with m1, mandible), Paracamelus sp. (partial metatarsal), Pseudodama sp. (partial antler and metacarpal), and Gazella subgutturosa (metatarsal) (Tong \& Chen 2015; Tong et al. 2017; Tong et al. 2018; Tong et al. 2011; Tong et al. 2012; Tong \& Wang 2014; Tong \& Zhang 2019).

Rancho La Brea Canis dirus. The best records of paleopathology in extinct canids are from the world's largest collection of late Pleistocene dire wolves, Canis dirus, from the Rancho La Brea asphalt seeps in Los Angeles, California, U.S.A. The Rancho La Brea paleopathology collection comprises about 3,200 specimens of dire wolves assembled from over 200,000 specimens representing a minimum of 3,500 individuals (dire wolves represent greater than $50 \%$ of all mammal specimens from Rancho La Brea) (Shaw \& Ware 2018). As the largest Canis that ever lived and presumably preferring larger prey, dire wolves are widely considered a social predator (Anyonge \& Roman 2006; Carbone et al. 2009; Hemmer 1978; Merriam 1912; Stock 1930; Van Valkenburgh \& Hertel 1998; Van Valkenburgh \& Sacco 2002). The Rancho La Brea dire wolf collection preserves a range of pathological conditions throughout the skeleton (Hartstone-Rose et al. 2015; Lawler et al. 2017; Moodie 1918; Shaw \& Howard 2015; Stock 1930; Ware 2005), 
114 with particularly debilitating examples offering evidence that strong social bonds existed to

115 allow weakened or disabled individuals to survive for extended periods of time (Shaw \& Howard

116 2015; Shaw \& Ware 2018).

117 Focusing on Canis dirus from a single deposit (Pit 61/67) at Rancho La Brea, Brown et al.

118 (2017) quantified patterns of traumatic pathology — injuries that likely resulted from hunting,

osteoarthritis - and predicted skull injuries to be common because of the probability of being kicked while chasing prey. Contrary to expectation, the cranium showed a low incidence of traumatic injury (1.6\%) and the dentary even less so (0.18\%) (Brown et al. 2017). This study, however, excluded dental injuries likely incurred from feeding — such as abscesses and alveolar resorption stemming from infection-which were also sustained by and preserved in C. dirus from Rancho La Brea. In the current study, we quantify these dental injuries, as well as traumatic damage to the dire wolf tibia, for comparison with dental and tibial injuries in C. chihliensis.

\section{Taxonomic and Phylogenetic Remarks}

As far as we are aware, there are few reports of debilitating injuries to large hypercarnivorous canines in the fossil record, including early Pleistocene Canis falconeri from Venta Micena of Spain (Palmqvist et al. 1999), Cuon from late Pleistocene of Italy (Iurino \& Sardella 2014), and the latest Pleistocene occurrences of Canis dirus in the Rancho La Brea asphalt seeps (Shaw \& Howard 2015). This is despite a generally excellent fossil record for large canids in the late Cenozoic because of canids' preference for mid-latitude open habitats, where terrestrial fossil records are best preserved and most extensively explored (Tedford et al. 2009; Wang 1994; Wang et al. 2008; Wang et al. 1999).

The holotype of Canis chihliensis was originally described based on a maxillary fragment with P3-M2 from Feng-Wo at Huang-Lu village (Locality 64) in Huailai County, Hebei (Chihli) Province by Zdansky (1924). Teilhard de Chardin \& Piveteau (1930) referred additional specimens to this species from Nihewan Basin. Rook (1994) synonymized $C$. chihliensis with $C$. antonii Zdansky, 1924, but Tedford et al. (2009) returned to C. chihliensis by restricting the concept to large Nihewan Canis. The systematics of $C$. chihliensis from SSMZ has been treated by Tong et al. (2012)

Rook (1994) and Sotnikova (2001) referred the Pliocene-Early Pleistocene species Canis falconeri from Europe, $C$. antonii from Asia and C. africanus from Africa to the supraspecific group Canis (Xenocyon) ex gr. falconeri. All of them readily fall into the category of hypercarnivores based on dentition and $C$. falconeri has also been hypothesized to be a hypercarnivore similar to modern gray wolves (Palmqvist et al. 1999). Canis chihliensis shares some similarities with Sinicuon dubius (Tong et al. 2012). Furthermore, C. chihliensis is among the largest Canis species of Eurasia in the early Pleistocene. 
152

153

154

155

156

157

158

159

160

161

162

163

164

165

166

167

168

169

170

171

172

173

174

175

176

177

178

179

180

181

182

183

184

185

186

187

188

189

\section{Results}

Dental Fracture and Inflammations as Related to Bone-crushing and Hypercarnivory. The left dentary (IVPP V17755.11) and right dentary (IVPP V17755.12) belong to the same individual. The left dentary (Fig. 1.A-D) has c, p1-3 and m2-3 intact, while the crown of p4, trigonid of $\mathrm{m} 1$, and mesial root of $\mathrm{m} 1$ are fractured and lost, apparently due to injuries suffered during life. Both root fragments of $\mathrm{p} 4$ are retained. On $\mathrm{m} 1$ only the talonid is preserved. Note on Fig 1.A that the alveolar bone in the region of the missing mesial root of $\mathrm{m} 1$ shows no residual socket, which indicates antemortem bone remodeling. This is consistent with the radiographic evidence of periapical bone resorption associated with the apices of the retained roots of $\mathrm{p} 4$ and the distal root of $\mathrm{ml}$ (described below). There is also partial loss of the enamel on $\mathrm{c}$ and $\mathrm{m} 1$ and fracturing of the crowns of $\mathrm{p} 2, \mathrm{p} 3$, and root of $\mathrm{m} 1$. The pulp cavities of $\mathrm{p} 4$ and $\mathrm{m} 1$ are exposed. The dentin of all teeth is stained brown. All remaining cusps are moderately worn.

There are multiple fractures of the buccal and lingual cortical surfaces of the dentary, primarily in the regions of p2-p3, m1-m2, and the posterior surface of the mandibular ramus including the condylar process. All fractures appear to be postmortem as suggested by the absence of any repair.

There is loss of the cortical bone on the alveolar ridge in the regions of $\mathrm{p} 3, \mathrm{p} 4$, and $\mathrm{m} 1$. This was most likely caused by periodontitis in vivo although there may have also been some postmortem fracturing of the alveolar bone around $\mathrm{m} 1$.

The right dentary (Fig. 1.E-H) preserves i2-3, c, p1-4, and m1-2 in situ; the crown of $\mathrm{m} 3$ is missing, but one root tip remains deep in the alveolus. The crown of $\mathrm{m} 1$ is brownish due to loss of most of the enamel cap, and with the pulp cavity exposed; $\mathrm{m} 2$ was broken during excavation; and other teeth are moderately worn. There are multiple fractures of the buccal and lingual cortical bone, predominantly in the regions of $\mathrm{p} 1$ and $\mathrm{m} 2$, that are postmortem defects.

The right dentary also suffered serious injury. The bone surrounding the $\mathrm{m} 1$ root is perforate on the buccal cortex (purple arrow, fpp, on Fig. 1.H) by an apparent fistula and there is extensive loss of alveolar bone over the buccal aspect of the mesial root of $\mathrm{m} 1$ (red arrow, pp, on Fig. 1.H). The buccal cortical surface is porous adjacent to $\mathrm{p} 4$ and $\mathrm{ml}$ (white arrows, vab, on Fig. 1.F). This is most likely the result of increased number and size of vascular canals associated with inflammation in this region.

Radiographic Observation. The radiographic images of the right and left dentaries reveal periapical bone loss (rarefying osteitis) (blue arrows, pi, on Figs. 1.D and 1.H) associated with exposed pulp cavities, a periodontal pocket between the right $\mathrm{p} 4$ and $\mathrm{m} 1$ (red arrow, pp, on Fig. 1.H), and an apparent fistula from the periodontal pocket to the surface (purple arrows, fpp, on Figs. 1.F and 1.H). 
190

191

192

193

194

195

196

197

198

199

200

201

202

203

204

205

206

207

208

209

210

211

212

213

214

215

216

217

218

219

220

221

222

223

224

225

226

227

228

229

Interpretation and Implications for Dental Injury. IVPP V17755 suffered from repeated dental injuries in similar locations on both left and right sides. Although both lever models and in vivo experimentation (Ellis et al. 2008) show that biting forces are greatest on the posterior-most molars, patterns of tooth wear suggest that the lower $\mathrm{p} 4-\mathrm{m} 1$ are used more frequently than more posterior molars (Tseng \& Wang 2010; Wang et al. 2008; Werdelin 1989), although in the case of the most hypercarnivorous canid, Lycaon, bone consumption may be at a more posterior location (Van Valkenburgh 1996). Dental modifications for bone consumption in fossil borophagine canids are most apparent in the $\mathrm{p} 4-\mathrm{m} 1$ region, indicating that this was the location of most bone-cracking behavior (Wang et al. 1999). We interpret the loss of the left p4-m1 in IVPP V17755 as owing to bone-cracking - the p4 and $\mathrm{m} 1$ are the largest lower cheek teeth in Canis and their loss must have been inflicted by a strong biting force. Preservation of the roots of both the $\mathrm{p} 4$ and the $\mathrm{m} 1$ trigonid (Fig. 1.D) suggests tooth fracture from a strong bite and/or encountering hard objects. The alveolar bone in the region of the missing $\mathrm{m} 1$ mesial root eventually healed, but the periapical infections associated with both retained root fragments of $\mathrm{p} 4$ and the distal root of $\mathrm{m} 1$ still show active lesions.

The need for bone-crushing in IVPP V17755 would have continued during and after the healing of the wounds on the left side. Accordingly, the right p4-m1 suffered excessive wear, likely to compensate for the loss of the same function on the left side. Again, we infer that the heavy wear is due to chewing on bones. The wear on the crown of $\mathrm{ml}$ led to exposure of the pulp chamber through two pulp horns in the mesial cusp and directly to the periapical lesions (abscess) (blue arrows, pi, in Figs. 1.D and 1.H). This lesion grew sufficiently that it created a fistula to the buccal surface of the dentary to allow drainage of pus. It is also likely that excessive use on the right side led to bone splinters (shards, fragments) being imbedded into the gum tissue between $\mathrm{p} 4$ and $\mathrm{m} 1$, causing a periodontal pocket.

The above scenario suggests prolonged and possibly repeated injuries and infections, first to the left p4-m1 (possibly broken in a single bite), and then to the right jaw perhaps after the left side had partially healed. Such a scenario is consistent with a hypercarnivorous dentition in $C$. chihliensis frequently used for bone consumption, as also seen in late Pleistocene European Cuon (Iurino \& Sardella 2014). Bone-crushing behavior in canids has been linked to collaborative hunting and competitive consumption of carcasses within the same family group of predators (Wang et al. 2008; Wang et al. 2018). Such a behavior is especially prevalent among large, hypercarnivorous canids, and Van Valkenburgh et al. (2019) recently linked high tooth fractures in extant gray wolves to limited prey availability.

Comparison to Rancho La Brea Canis dirus. In Pit 61/67 alone, 35 dentaries of adult age (14 left, 21 right) _ out of 64 pathological adult dentaries (25 left, 39 right; 55\%) and 617 dentaries total (both pathological and non-pathological; 5.7\%) - exhibit dental injuries similar to those in the Nihewan C. chihliensis dentaries examined in this current study (Fig. S3). Across Rancho La Brea deposits, abscesses and alveolar resorption likely due to infection were preserved in $43 \%$ (Pit 16) to 77\% (Pit 3) of pathological dentaries (Fig. 2.A). Most of the remaining pathological 
230 dentaries also preserved dental anomalies, predominantly supernumerary teeth (particularly in

231 the first and second premolars) or a missing lower first premolar (p1) and/or third molar (m3).

232 Because both the p1 and m3 (Balisi et al. 2018; Buchalczyk et al. 1981; Wang 1994) vary in their

233 presence among canids, we excluded anomalies in these teeth from our comparison with

234 Nihewan $C$. chihliensis. Across 200 C. dirus jaws (both left and right) bearing abscesses and

235 alveolar infections, the lower first molar or carnassial showed the highest frequency of injury (87

236 total specimens with $\mathrm{m} 1$-associated injuries), likely inflicted by bone-crushing during the

237 consumption of prey, followed by the second premolar ( 79 total specimens with p2-associated

238 injuries), likely the result of biting and killing while chasing prey or in fighting with conspecifics

239 or competitors of other species (Fig. 2.B). The fourth premolar was the third most frequently

240 injured tooth (57 specimens); often, it was injured in conjunction with the lower first molar (34

241 specimens), as in the case of $C$. chihliensis. As $C$. dirus is a predator widely recognized to have

242 had a forceful bite capable of processing bone (Anyonge \& Baker 2006; Brannick et al. 2015;

243 Van Valkenburgh \& Hertel 1993), the high frequency of injury in its p4-m1 complex — similar to

244 that found in the specimens of $C$. chihliensis examined here-supports the inference that $C$.

245 chihliensis also processed bone using $\mathrm{p} 4$ and $\mathrm{m} 1$.

246

247

248

249

250

251

252

253

254

255

256

257

258

259

260

261

262

263

264

265

266

267

268

269
Tibia Fracture. A normal left tibia (IVPP V18139.21) and pathologic right tibia (IVPP V18139.20) of Canis are present in the collection from Shanshenmiaozui (SSMZ). The pathologic tibia has healed fractures at the lower one-third of the shaft. Compared with the normal tibia on the left side (Fig. 3), the pathologic tibia is stouter; it is much broader distally, especially at the fracture site, and is shorter, the maximum length for the normal tibia being $181.6 \mathrm{~mm}$, in contrast to the pathologic one at $166.5 \mathrm{~mm}$ (Table 1). In addition, the nutrient foramen is much more enlarged in the pathologic tibia. The partially healed bone has a rough and porous surface (callus).

The porous bone surface indicates that the periosteal vessels also took part in the repair of the fracture, which penetrated into the hard callus. Because the woven/primary bone is not replaced with secondary lamellar bone, this individual did not survive to the stage of lamellar bone formation, i.e. the fracture healing stage 6 by Edge-Hughes \& Nicholson (2007).

Foreshortening of tibia. The pathologic tibia has fused overlapping components with remodeling starting $4 \mathrm{~cm}$ from the proximal surface and extending throughout the length. Accentuation (irregularities) of the entheseal region at the lateral margin of the tibial plateau suggests increased stress at the proximal tibial-fibular joint. The tibia widens abnormally starting $6 \mathrm{~cm}$ distal to proximal surface, with concurrent alteration of surface color and texture, continuing on to the fused distal component of the tibial fracture, where surface filigree reaction (characteristic of infection) is more prominent. There are increased vascular markings at the junction of the proximal and middle third (related to current length) of the tibia. A shallow groove identifies the original demarcation of the fracture components now fused. The fibula was also fractured, and residual components are noted at the distal $6 \mathrm{~cm}$. A linear defect is noted at

Peer] reviewing PDF | (2020:05:48717:2:0:NEW 5 Aug 2020) 
270 the mid-portion of the tibia, slightly medial to the sagittal line. It appears to be perforated in a

271 manner more suggestive of vasculature than of draining sinuses. It may be the residue of the

272 fracture. If so, it would mean that the injury not only caused fracture, separation and overlap of

273 components, but also caused a "splintering" or at least slight separation of the distal portion of

274 the proximal component. Increased vascularity is noted $2 \mathrm{~cm}$ from the distal end of the tibia.

275

276

277

278

279

280

281

282

283

284

285

286

287

288

289

290

291

292

293

294

295

296

297

298

299

300

301

302

303

304

305

306

307

308

309

X-ray Examination. Increased density of the medial tibial plateau is noted. If not related to an artifact (e.g., glued component), this is suggestive of a healed, minimally displaced fracture. There clearly is a displaced distal fracture, fused incompletely with overlap. The curvature of the distal portion of the proximal component suggests torsion of the components related to each other. Several layers of periosteal reaction are noted, with partial disruption of subjacent cortex. The distal fibula is fused to the tibia, with focal loss of margin definition. Irregular cavities are noted in the distal portion of the proximal component of the fracture and adjacent to the distal junction of the tibia and fibula. Both contain radio-dense material. This suggests that this was a compound fracture, with skin breach and exposure to environmental contamination. The fracture was incompletely stabilized during the healing process, with continued movement of the components.

CT Scan. The CT images show clearly that it was a comminuted fracture, and all three pieces of the fractures are displaced, which resulted in the division of the medullary cavity into three chambers whose broken ends were enclosed by callus or woven bones (Figs. 4.A-D).

CT longitudinal sections slice 1 (Figs. 4.A-B) - There is a focal area of trabecular loss just distal to the proximal epiphyseal plate. It is irregularly ellipsoid in shape and contains slightly thickened bone "fragments" of apparently increased density. Increased density is noted in the subsequent proximal fracture component. Periosteal reaction is noted with multiple focal areas of trabecular loss, bounded by sclerotic margins, characteristic of abscesses. There is massive loss of cortical bone in the region of fragment fusion. Fibular fusion with a distal radio-dense inclusion is noted. Presence of foreign bodies is consistent with the diagnosis of a compound fracture.

CT longitudinal sections slice 2 (Figs. 4.C-D) - There is an area of increased density at the median tibial plateau noted on the x-ray. The CT shows this area to be separated by a fracture line from subjacent bone. The trabecular pattern is denser. The lateral portion of the proximal epiphyseal plate is partially preserved, in contrast to the medial portion, which cannot be distinguished from the epiphysis. This appears to be a non-displaced fracture through the epiphyseal plate, only affecting a portion of that plate.

There is a linear focal disruption (partially occluded at the surface) of the medial aspect at the midpoint of the current length and a U-shaped defect (also seen in CT slice 1) with thickened margins at the distal fifth. The latter could represent a draining abscess, although the former suggests the possibility of a penetrating injury. Radio-dense inclusions are noted, perhaps representing environmental exposure at time of injury. The surface imperfection seen on the 
310 reconstructed tibial image (Fig. 4.E) may be a CT averaging artifact. A series of 8 cross sections

311 (Figs. 4.F-M) allows comparisons of healthy cancellous (F), healthy cortical (G-H), and injured 312 and healed bones (I-M).

313

314

315

316

317

318

319

320

321

322

323

324

325

326

327

328

329

330

331

332

333

334

335

336

337

338

339

340

341

342

343

344

345

346

347

Interpretation, Comparison, and Implications for Limb Injury. That the injury, plus the subsequent infections, suffered by IVPP V18139 must have been devastating seems not in doubt. The displacement of the right hindlimb and the pain associated with a compound fracture with skin breach and exposure to environmental contamination all but rule out hunting activities. For modern domestic dogs of more than 1 year of age, fracture healing can take 7 weeks to 1 year (Edge-Hughes \& Nicholson 2007). Therefore, it is safe to assume that healing of the open fractures in IVPP V18139 without medical intervention (broken bones not re-aligned nor cast to immobilize wounds) would take a considerable amount of time, much longer than its metabolic reserve can sustain. Such a long-term survival by an injured wolf requiring a high degree of meat consumption thus suggests collaborative hunting and potentially family care.

In addition to abnormalities in the jaws and dentition, the Rancho La Brea dire wolf collection has numerous healed fractures in the limb bones (Moodie 1918; Shaw \& Howard 2015; Stock 1930; Ware 2005). Again focusing on Pit 61/67, which has a minimum number of 371 dire wolf individuals, Brown et al. (2017) showed that frequencies of traumatic injuryincluding healed fractures - were higher than expected for most limb bones, especially the tibia. Surveying dire wolf tibiae across all Rancho La Brea deposits, we found 11 specimens (5 left, 6 right) of 251 total pathologic tibiae (4.38\%) to have suffered an oblique fracture with foreshortening similar to that in IVPP V18139 (Fig. S4). In studies of modern Saskatchewan gray wolves and sympatric coyotes, such bone fractures - which likely resulted from conflicts with large prey - were found to be more common in wolves than in coyotes, a difference thought to result from wolves' tendency to prey on larger animals like moose (Wobeser 1992). Similarly, Rancho La Brea preserves no fractured and healed tibiae belonging to the coyote- which is also found abundantly in the Pleistocene to Holocene-age asphalt seeps - though this lack may be confounded by a coyote sample size an order of magnitude smaller than that of the dire wolf.

\section{Discussions}

Life is not easy for large predators. In modern canids, hypercarnivory is almost always associated with social hunting, such as in the gray wolves (Canis lupus), African hunting dogs (Lycaon pictus), and Asiatic dholes (Cuon alpinus). Of these, the latter two most hypercarnivorous species almost invariably hunt cooperatively, whereas gray wolves regularly, but not exclusively, hunt together for large prey (Macdonald 1983). Group hunting by these highly social canids offers apparent advantages that are otherwise unavailable to individual hunters, such as the ability to bring down prey much larger than the predators themselves, plus coordinated attacks that seal off escape routes as well as relaying strategies that lessen the burden of individual hunters. These strategies are especially critical to canids because, unlike felids,

Peer] reviewing PDF | (2020:05:48717:2:0:NEW 5 Aug 2020) 
348

349

350

351

352

353

354

355

356

357

358

359

360

361

362

363

364

365

366

367

368

369

370

371

372

373

374

375

376

377

378

379

380

381

382

383

384

385

386

387

canids never evolved fully retractile claws that are effective weapons for grappling with and subduing prey (Wang 1993). Therefore, for canids, group hunting is not optional, as it is for large cats (only the lions are social hunters, as are occasionally the cheetahs), once canids have crossed the critical body mass threshold of about $21 \mathrm{~kg}$ above which energetic costs necessitate feeding on large prey (Carbone et al. 1999). For canids, it is possible that this body size threshold may even be substantially lowered as in the case of the Asiatic dholes (10-13 kg) that have the most extremely hypercarnivorous dentitions among living canids (Cohen 1978). The Nihewan Canis chihliensis is larger than the dholes (13.7-16.8 kg based on femur shaft diameter; $21.2 \mathrm{~kg}$ based on the mean of $\mathrm{m} 1$ length).

Social hunting is characteristic of large canids, hyaenids, and some felids, and depending on how such behavior is described, may even be quite common in carnivorans (Bailey et al. 2013). Such behavior has important implications not only in the social organizations of large carnivorans but also in their trophic relationships and diet. Among large, hypercarnivorous living canids, the gray wolf (Canis lupus) is the best studied in its pack hunting behavior. The basic social unit is the mated pair; prey size is a factor in pack sizes, which range from a few up to 20 individuals, with the largest packs preying on bison and moose and smaller packs preying on deer (Mech \& Boitani 2003). Social hunting, however, may not always be the most efficient in terms of food intake per wolf because the packs must share their proceeds (Thurber \& Peterson 1993). The formation of packs, therefore, offers the opportunity to kill prey too large to tackle by one individual alone, as well as the opportunity both to better defend kills against carcass theft and to steal carcasses from larger predators (Carbone et al. 1997; Eaton 1979; Van Valkenburgh 2001; Vucetich et al. 2004).

It has been long known that large Canis from the Nihewan Basin includes individuals with highly trenchant lower molars (Teilhard de Chardin \& Piveteau 1930). Hypercarnivorous characteristics (dominance of cutting edge of $\mathrm{m} 1$ trigonid and enlargement of hypoconid at the expense of entoconid, along with reductions of posterior molars) in C. chihliensis are variable (Tong et al. 2012) but strongly converge on the morphology of living African hunting dogs and Asiatic dholes (Fig. 5). Such a dental morphology is commonly associated with emphasis in slicing meat using the sharp carnassial blades. Trenchant molars thus correlate well with hypercarnivory (Crusafont-Pairó \& Truyols-Santonja 1956), i.e., tendency to consume meat exclusively, which also drives the evolution of larger body size as a macroevolutionary ratchet (Van Valkenburgh et al. 2004).

Wolves have a dangerous life as long-distance pursuit predators. The traumas and infections inflicted on Canis chihliensis likely are related to hunting behavior, feeding strategies, and predator-prey interactions, as have also been suggested for other extinct carnivores (Shaw \& Ware 2018). Healing from such devastating injuries is also a testimony to its survival for long periods of time during which the ability to hunt must have been seriously limited or nonexistent, suggesting that assisted living was a possibility. Debilitating bone diseases in the Pleistocene apex predator Smilodon, which were even more hypercarnivorous than canids, have also been used to argue for social or gregarious behaviors (Akersten 1985; Heald 1989; Shaw 1992a; Shaw 
388

389

390

391

392

393

394

395

396

397

398

399

400

401

402

403

404

405

406

407

408

409

410

411

412

413

414

415

416

417

418

419

420

421

422

423

424

425

426

427

1992b; Van Valkenburgh 2009; Van Valkenburgh \& Sacco 2002) although the pathologysociality link has been challenged (McCall et al. 2003). Schleidt \& Shalter (2004) also noted that social predators should have more healed injuries than solitary predators. Often infirm animals are allowed to feed on group kills, as observed in spotted hyaenas and African wild dogs.

Whereas sociality in sabertooth cats has been questioned given its rarity among extant large felids, all of which are capable of killing on their own, pack hunting in dog-like carnivorans (wolves, hunting dogs, dholes, hyenas) is the dominant mode of predation and may partly be driven by the necessity of overcoming larger prey (Mech \& Boitani 2003). Dental morphology and pathology in our Nihewan Canis chihliensis strongly suggest processing of hard food (bone cracking), which is commonly associated with hypercarnivory and pack hunting in large canids. While herbivores, too, suffer from crippling injuries, comparisons to herbivores are irrelevant in this case because injured herbivores can continue eating plant matter, foraging on food items that do not move, while recovering from injuries. However, critical carnivore injuries, such as to the running hindlimbs, blunt active predators' ability to hunt and chase animal prey. Although the massive, healed tibial fracture may not be a definitive indication of social care, a predator's recovery from such a devastating injury is suggestive of food provisioning that only social groups can offer. This has been similarly proposed from an early Pleistocene Spanish record of C. falconeri (Palmqvist et al. 1999), although temporary shift to a more omnivorous diet is also possible. With this new record from Nihewan, we extend the history of Canis sociality to the early Pleistocene, and likely to the Pliocene as well if the even larger Canis antonii from Fugu area in Shanxi Province is taken into consideration (Tedford et al. 2009:appendix I).

Arguably the most definitive (though still correlative) pathological evidence to support sociality in Canis chihliensis would be a significant prevalence of similar injuries not only in the extinct Canis dirus but in the three extant hypercarnivorous canines whose pack-hunting behavior can be observed directly, in contrast to a low prevalence of similar injuries in non-packhunting carnivoran species. However, one common challenge in predator paleopathology is the lack of sufficient samples of large-predator post-crania relative to crania in museum collections of living mammals. Survival with just the leg or just the dental damage does have isolated representation, but not the combination. Museum records of similar injuries and survivals undoubtedly exist for non-bone-crunching and non-social species as well (but published documentation is often lacking) and a definitive inference is not possible without more detailed records, both extant and extinct. This limitation - and the corresponding lack of published systematic pathological surveys across large sample sizes within and among extant speciesprevents statistically robust inferences of injury prevalence in extant wild animals. When isolated cases are available, lack of field documentation on behaviors related to pathological specimens also hampers interpretations. Such deficiencies make it difficult to ground-truth inferences of extinct behaviors based on extant relatives, even where large samples of extinct predators are available (Brown et al. 2017). While such a systematic comparative survey exceeds the scope of the current paper, future studies that calculate injury prevalence across large museum and zoo collections of extant species of known behavior (e.g., Rothschild et al. 1998) would bolster 
428

429

430

431

432

433

434

435

436

437

438

439

440

441

442

443

444

445

446

447

448

449

450

451

452

453

454

455

456

457

458

459

460

461

462

463

464

465

inferences of extinct behavior based on skeletal injuries.

As knowledge of the fossil history of hypercarnivorous canids in the Plio-Pleistocene of Eurasia increases, more complexity than has been previously assumed is now emerging, both in its chronology and its morphologic diversity. Recent molecular studies placed Cuon and Lycaon, two of the most hypercarnivorous living canids, near the base of the Canis clade (Chavez et al. 2019; Koepfli et al. 2015; Lindblad-Toh et al. 2005), in contrast to morphological analysis suggesting that hypercarnivorous forms are at the terminal end of the canine phylogeny (Tedford et al. 1995; Tedford et al. 2009). If the molecular relationship is correct, then records of Cuon and Lycaon are expected to be at least as old, if not older, than that of many species of Canis. This new record pushes back the first occurrence of pack hunting likely accompanied by social care by about 1.7 million years to when early Homo erectus was first recorded in Asia (Ao et al. 2013; Zhu et al. 2004). This record is important because it coincides with the initial diversification of the large canids (such as Canis and Lycaon), also known as the Wolf Event in Eurasia (Azzaroli 1983; Sardella \& Palombo 2007), and Lycaon's arrival in Africa (HartstoneRose et al. 2010).

Although records of early wolves have been pushed back slightly (Martínez-Navarro et al. 2009; Rook \& Martínez-Navarro 2010; Sardella \& Palombo 2007), the wolf event is essentially confined to the Early Pleistocene, i.e., Late Pliocene before recent redefinition (Gibbard et al. 2010). A recent new Tibetan record in the Middle Pliocene, Sinicuon cf. S. dubius, seems to suggest that hypercarnivorous canines may have predated the genus Canis (Wang et al. 2014). Whatever the detailed relationships of these records, it seems clear that hyper-predators, such as large wolves and hunting dogs, were associated with the increasingly open habitats in Eurasia during the onset of the Pleistocene. In this background of large-canine radiation at the beginning of the Ice Age, our new record of a pathological wolf from the Early Pleistocene of Nihewan hints at pack hunting as a major step toward social collaboration while procuring food and, as such, signals a major step in the evolution of large canids.

\section{Conclusions}

We document dental injuries and infections and a healed tibia fracture in Canis chihliensis from the early Pleistocene ( 1.2 Ma) Nihewan Basin of northern China. This early species of wolf-like Canis signals the evolution of large body size and hypercarnivorous dentition in the genus. The dental injuries and infections likely occurred while processing hard food, such as bones, whereas the tibia fractures would have severely limited locomotion during recuperation. Dental injuries and healing of compound fracture supports social hunting and family care (food-sharing) although alternative explanations exist because similar injuries likely appear in non-bone crunching and non-social species as well. Comparisons with abundant paleopathological records of the putatively pack-hunting late Pleistocene dire wolf, Canis dirus, at Rancho La Brea in southern California demonstrates similarity in feeding behavior and sociality between Chinese and American Canis across space and time. 
466

467

468

469

470

471

472

473

474

475

476

477

478

479

480

481

482

483

484

485

486

487

488

489

490

491

492

493

494

495

496

497

498

499

500

501

502

503

504

505

\section{Acknowledgments}

The authors wish to express their thanks to the following people and organizations for their help: Han F., Sun B. Y., Lü D., Sun J. J., Xu Z. J., Qiu Z. W., Wang Q. Y., Sun B. H., Hu N., Liu X. T. \& Yin C. for participating the fieldwork; Xie F. of HPICR, Zhao W. J. of NNNRM and Hou W. Y. of NM for help during excavations; Qiu Z. X., Wei Q. for sharing bibliographies and/or for fruitful discussions; Hou Y. M. for CT scanning; F. Heald and C. Shaw for initial diagnosis and assembly of the Rancho La Brea pathology collection; A. Farrell and G. Takeuchi for Rancho La Brea collections access; B. Van Valkenburgh for thoughtful critique. We are grateful to Julie Meachen, Josh Samuels, and an anonymous reviewer (who kindly reviewed our paper twice) for their critical reviews and comments, and editor Virginia Abdala for her editorial suggestions.

\section{References}

Akersten WA. 1985. Canine function in Smilodon (Mammalia: Felidae: Machairodontinae). Natural History Museum of Los Angeles County Contributions in Science 356:1-22.

Anyonge W, and Baker A. 2006. Craniofacial morphology and feeding behavior in Canis dirus, the extinct Pleistocene dire wolf. Journal of Zoology 269:309-316.

Anyonge W, and Roman C. 2006. New body mass estimates for Canis dirus, the extinct Pleistocene dire wolf. Journal of Vertebrate Paleontology 26:209-212.

Ao H, An Z, Dekkers MJ, Li Y, Xiao G, Zhao H, and Qiang X. 2013. Pleistocene magnetochronology of the fauna and Paleolithic sites in the Nihewan Basin: Significance for environmental and hominin evolution in North China. Quaternary Geochronology 18:78-92. http://dx.doi.org/10.1016/j.quageo.2013.06.004

Azzaroli A. 1983. Quaternary mammals and the "end-Villafranchian" dispersal event - A turning point in the history of Eurasia. Palaeogeography, Palaeoclimatology, Palaeoecology 44:117-139. http://dx.doi.org/10.1016/0031-0182(83)90008-1

Bailey I, Myatt JP, and Wilson AM. 2013. Group hunting within the Carnivora: physiological, cognitive and environmental influences on strategy and cooperation. Behavioral Ecology and Sociobiology 67:1-17. 10.1007/s00265-012-1423-3

Balisi M, Wang X, Sankey J, Biewer J, and Garber D. 2018. Fossil canids from the Mehrten Formation, Late Cenozoic of Northern California. Journal of Vertebrate Paleontology 36:e1405009. 10.1080/02724634.2017.1405009

Brannick AL, Meachen JA, and O'Keefe FR. 2015. Microevolution of jaw shape in the dire wolf, Canis dirus, at Rancho La Brea. Natural History Museum of Los Angeles County Science Series 42:23-32.

Brown C, Balisi M, Shaw CA, and Van Valkenburgh B. 2017. Skeletal trauma reflects hunting behaviour in extinct sabre-tooth cats and dire wolves. Nature Ecology \& Evolution 1:0131. 10.1038/s41559-017-0131

Buchalczyk T, Dynowski J, and Szteyn S. 1981. Variations in number of teeth and asymmetry of the skull in the wolf. Acta Theriologica 26:23-30. 
506

507

508

509

510

511

512

513

514

515

516

517

518

519

520

521

522

523

524

525

526

527

528

529

530

531

532

533

534

535

536

537

538

539

540

541

542

543

544

545

546

547

548

549

550

551

Carbone C, Du Toit JT, and Gordon IJ. 1997. Feeding success in African Wild Dogs: Does kleptoparasitism by spotted hyenas influence hunting group size? Journal of Animal Ecology 66:318-326. 10.2307/5978

Carbone C, Mace GM, Roberts SC, and Macdonald DW. 1999. Energetic constraints on the diet of terrestrial carnivores. Nature 402:286-288.

Carbone C, Maddox T, Funston PJ, Mills MGL, Grether GF, and Valkenburgh BV. 2009. Parallels between playbacks and Pleistocene tar seeps suggest sociality in an extinct sabretooth cat, Smilodon. Biology Letters 5:81-85. doi:10.1098/rsbl.2008.0526

Chavez DE, Gronau I, Hains T, Kliver S, Koepfli K-P, and Wayne RK. 2019. Comparative genomics provides new insights into the remarkable adaptations of the African wild dog (Lycaon pictus). Scientific Reports 9:8329. 10.1038/s41598-019-44772-5

Chen X. 2018. Taphonomic study of Early Pleistocene Shanshenmiaozui fossil site in Nihewan Basin, North China Ph.D. University of Chinese Academy of Sciences.

Chen X, and Tong H-w. 2015. Taphonomy of the Canis chihliensis fossil assemblage from the Shanshenmiaozui Site, Nihewan Basin. Acta Anthropologica Sinica 34:553-564.

Cohen JA. 1978. Cuon alpinus. Mammalian Species 100:1-3.

Crusafont-Pairó M, and Truyols-Santonja J. 1956. A biometric study of the evolution of fissiped carnivores. Evolution 10:314-332.

Eaton RL. 1979. Interference competition among carnivores: A model for the evolution of social behavior. Carnivore 2:9-16.

Edge-Hughes L, and Nicholson H. 2007. 13, Canine treatment and rehabilitation. In: McGowan CM, Goff L, and Stubbs N, eds. Animal Physiotherapy: Assessment, Treatment and Rehabilitation of Animals. Oxford: Blackwell Publishing, 207-234.

Ellis JL, Thomason JJ, Kebreab E, and France J. 2008. Calibration of estimated biting forces in domestic canids: comparison of post-mortem and in vivo measurements. Journal of Anatomy 212:769-780. 10.1111/j.1469-7580.2008.00911.x

Gibbard PL, Head MJ, Walker MJC, Alloway B, Beu AG, Coltorti M, Hall VM, Liu J-q, Knudsen KL, Van Kolfschoten T, Litt T, Marks L, McManus J, Partridge TC, Piotrowski JA, Pillans B, Rousseau D-D, Suc JP, Tesakov AS, Turner C, and Zazo C. 2010. Formal ratification of the Quaternary System/Period and the Pleistocene Series/Epoch with a base at 2.58 Ma. Journal of Quaternary Science 25:96-102. 10.1002/jqs. 1338

Gipson PS, Ballard WB, and Mech RMND. 2000. Accuracy and precision of estimating age of gray wolves by tooth wear. Journal of Wildlife Management 64:752-758.

Hartstone-Rose A, Dundas RG, Boyde B, Long RC, Farrell AB, and Shaw CA. 2015. The bacula of Rancho La Brea. Natural History Museum of Los Angeles County Science Series 42:53-63.

Hartstone-Rose A, Werdelin L, De Ruiter DJ, Berger LR, and Churchill SE. 2010. The PlioPleistocene ancestor of wild dogs, Lycaon sekowei n. sp. Journal of Paleontology 84:299308. 10.1666/09-124.1

Heald FP. 1989. Injuries and diseases in Smilodon californicus Bovard, 1904 (Mammalia Felidae) from Rancho la Brea, California. Journal of Vertebrate Paleontology 9:24A.

Hemmer H. 1978. Considerations on sociality in fossil carnivores. Carnivore 1:105-107.

Iurino DA, and Sardella R. 2014. Medical CT scanning and the study of hidden oral pathologies in fossil carnivores. Paläontologische Zeitschrift 89:251-259.

Koepfli K-P, Pollinger J, Godinho R, Robinson J, Lea A, Hendricks S, Schweizer Rena M, Thalmann O, Silva P, Fan Z, Yurchenko Andrey A, Dobrynin P, Makunin A, Cahill

Peer] reviewing PDF | (2020:05:48717:2:0:NEW 5 Aug 2020) 
552

553

554

555

556

557

558

559

560

561

562

563

564

565

566

567

568

569

570

571

572

573

574

575

576

577

578

579

580

581

582

583

584

585

586

587

588

589

590

591

592

593

594

595

596

James A, Shapiro B, Álvares F, Brito José C, Geffen E, Leonard Jennifer A, Helgen Kristofer M, Johnson Warren E, O'Brien Stephen J, Van Valkenburgh B, and Wayne Robert K. 2015. Genome-wide evidence reveals that African and Eurasian golden jackals are distinct species. Current Biology 25:2158-2165. 10.1016/j.cub.2015.06.060

Lawler DF, Widga C, and Smith GK. 2017. Observations of the acetabulum and proximal femur of the dire wolf (Canis dirus, Leidy 1854). Journal of Veterinary Anatomy 10:73-83.

Lindblad-Toh K, Wade CM, Mikkelsen TS, Karlsson EK, Jaffe DB, Kamal M, Clamp M, Chang JL, Kulbokas EJ, Zody MC, Mauceli E, Xie X, Breen M, Wayne RK, Ostrander EA, Ponting CP, Galibert F, Smith DR, deJong PJ, Kirkness E, Alvarez P, Biagi T, Brockman W, Butler J, Chin C-W, Cook A, Cuff J, Daly MJ, DeCaprio D, Gnerre S, Grabherr M, Kellis M, Kleber M, Bardeleben C, Goodstadt L, Heger A, Hitte C, Kim L, Koepfli K-P, Parker HG, Pollinger JP, Searle SMJ, Sutter NB, Thomas R, Webber C, and Lander ES. 2005. Genome sequence, comparative analysis and haplotype structure of the domestic dog. Nature 438:803-819.

Liu P, Wu Z, Deng C, Tong H, Qin H, Li S, Yuan B, and Zhu R. 2016. Magnetostratigraphic dating of the Shanshenmiaozui mammalian fauna in the Nihewan Basin, North China. Quaternary International 400:202-211. https://doi.org/10.1016/j.quaint.2014.09.024

Macdonald DW. 1983. The ecology of carnivore social behaviour. Nature 301:379-384. $10.1038 / 301379 \mathrm{a} 0$

Martínez-Navarro B, Belmaker M, and Bar-Yosef O. 2009. The large carnivores from 'Ubeidiya (early Pleistocene, Israel): biochronological and biogeographical implications. Journal of Human Evolution 56:514-524. http://dx.doi.org/10.1016/j.jhevol.2009.02.004

McCall S, Naples V, and Martin L. 2003. Assessing behavior in extinct animals: Was Smilodon social? Brain, Behavior and Evolution 61:159-164. 10.1159/000069752

Mech LD, and Boitani L. 2003. Wolf social ecology. In: Mech LD, and Boitani L, eds. Wolves, Behavior, Ecology, and Conservation. Chicago: University of Chicago Press, 1-34.

Merriam JC. 1912. The fauna of Rancho la Brea, Part II. Canidae. Memoirs of the University of California 1:218-262.

Mescher AL. 2018. Junqueira's Basic Histology: Text and Atlas, 15th Edition. New York: McGraw-Hill Education.

Moodie RL. 1918. Paleontological evidences of the antiquity of disease. The Scientific Monthly 7:265-281.

Palmqvist P, Arribas A, and Martínez-Navarro B. 1999. Ecomorphological study of large canids from the lower Pleistocene of southeastern Spain. Lethaia 32:75-88.

Qiu Z-x. 2000. Nihewan fauna and Q/N boundary in China. Quaternary Sciences 20:154-163.

Rook L. 1994. The Plio-Pleistocene Old World Canis (Xenocyon) ex gr. falconeri. Bollettino della Società Paleontologica Italiana 33:71-82.

Rook L, and Martínez-Navarro B. 2010. Villafranchian: The long story of a Plio-Pleistocene European large mammal biochronologic unit. Quaternary International 219:134-144. http://dx.doi.org/10.1016/j.quaint.2010.01.007

Rothschild BM, Rothschild C, and Woods RJ. 1998. Inflammatory arthritis in large cats: An expanded spectrum of spondyloarthropathy. Journal of Zoo and Wildlife Medicine 29:279-284.

Rothschild BM, Wang X, and Shoshani J. 1994. Spondyloarthropathy in proboscideans. Journal of Zoo and Wildlife Medicine 25:360-366. 
597

598

599

600

601

602

603

604

605

606

607

608

609

610

611

612

613

614

615

616

617

618

619

620

621

622

623

624

625

626

627

628

629

630

631

632

633

634

635

636

637

638

639

640

641

642
Sardella R, and Palombo MR. 2007. The Pliocene-Pleistocene boundary: which significance for the so called "Wolf Event"? Evidences from Western Europe. Quaternaire 18:65-71.

Schleidt WM, and Shalter MD. 2004. Co-evolution of humans and canids, An alternative view of dog domestication: Homo Homini Lupus? Evolution and Cognition 9:57-72.

Shaw CA. 1992a. Old wounds: the paleopathology of Rancho la Brea. Terra 31:17.

Shaw CA. 1992b. The sabertoothed cat. Terra 31:26.

Shaw CA, and Howard C. 2015. Facial asymmetry in the sabercat (Smilodon fatalis) and wolf (Canis dirus) from Rancho la Brea, Los Angeles, California. PaleoBios 32:15.

Shaw CA, and Ware CS. 2018. Chapter 11, Smilodon paleopathology: A summary of research at Rancho La Brea. In: Werdelin L, McDonald HG, and Shaw CA, eds. Smilodon, the Iconic Sabertooth. Baltimore: Johns Hopkins University Press, 196-206.

Sotnikova MV. 2001. Remains of Canidae from the lower Pleistocene site of Untermassfeld. In: Kahlke R-D, ed. Das Pleistozäne von Untermassfeld bei Meiningen (Thüringgen) Teil 2. Mainz: Römisch-Germanischen Zentralmuseums, 607-632.

Stock C. 1930. Rancho la Brea: a record of Pleistocene life in California. Los Angeles County Museum of Natural History Science Series 20:1-81.

Summer-Smith G. 1966. Observations on epiphyseal fusion of the canine appendicular skeleton. Journal of Small Animal Practice 7:303-311.

Tedford RH, Taylor BE, and Wang X. 1995. Phylogeny of the Caninae (Carnivora: Canidae): the living taxa. American Museum Novitates 3146:1-37.

Tedford RH, Wang X, and Taylor BE. 2009. Phylogenetic systematics of the North American fossil Caninae (Carnivora: Canidae). Bulletin of the American Museum of Natural History 325:1-218.

Teilhard de Chardin P, and Piveteau J. 1930. Les mammifères fossiles de Nihowan (Chine). Annales de Paléontologie 19:1-134.

Thurber JM, and Peterson RO. 1993. Effects of population density and pack size on the foraging ecology of gray wolves. Journal of Mammalogy 74:879-889. 10.2307/1382426

Tong H-w, and Chen X. 2015. On newborn calf skulls of Early Pleistocene Mammuthus trogontherii from Shanshenmiaozui in Nihewan Basin, China. Quaternary International 406, Part B:57-69. http://dx.doi.org/10.1016/j.quaint.2015.02.026

Tong H-w, Chen X, and Zhang B. 2017. New fossils of Bison palaeosinensis (Artiodactyla, Mammalia) from the steppe mammoth site of Early Pleistocene in Nihewan Basin, China. Quaternary International 445:250-268. https://doi.org/10.1016/j.quaint.2016.07.033

Tong H-w, Chen X, and Zhang B. 2018. New postcranial bones of Elasmotherium peii from Shanshenmiaozui in Nihewan Basin, Northern China. Quaternaire 29:195-204.

Tong H-w, Hu N, and Han F. 2011. A preliminary report on the excavation at the Early Pleistocene fossil site of Shanshenmiaozui in Nihewan Basin, Hebei, China. Quaternary Sciences 31:643-653.

Tong H-w, Hu N, and Wang X. 2012. New remains of Canis chihliensis (Mammalia, Carnivora) from Shanshenmiaozui, a lower Pleistocene site in Yangyuan, Hebei. Vertebrata PalAsiatica 50:335-360.

Tong H-w, and Wang X-m. 2014. Juvenile skulls and other postcranial bones of Coelodonta nihowanensis from Shanshenmiaozui, Nihewan Basin, China. Journal of Vertebrate Paleontology 34:710-724. 10.1080/02724634.2013.814661

Tong H-w, and Zhang B. 2019. New fossils of Eucladoceros boulei (Artiodactyla, Mammalia) from Early Pleistocene Nihewan Beds, China. Palaeoworld 28:403-424.

PeerJ reviewing PDF | (2020:05:48717:2:0:NEW 5 Aug 2020) 
643

644

645

646

647

648

649

650

651

652

653

654

655

656

657

658

659

660

661

662

663

664

665

666

667

668

669

670

671

672

673

674

675

676

677

678

679

680

681

682

683

684

685

686

Tseng ZJ, and Wang X. 2010. Cranial functional morphology of fossil dogs and adaptation for durophagy in Borophagus and Epicyon (Carnivora, Mammalia). Journal of Morphology 271:1386-1398.

Van Valkenburgh B. 1990. Skeletal and dental predictors of body mass in carnivores. In: Damuth J, and MacFadden BJ, eds. Body Size in Mammalian Paleobiology: Estimation and Biological Implications. Cambridge: Cambridge University Press, 181-206.

Van Valkenburgh B. 1991. Iterative evolution of hypercarnivory in canids (Mammalia: Carnivora): evolutionary interactions among sympatric predators. Paleobiology 17:340362.

Van Valkenburgh B. 1996. Feeding behavior in free-ranging, large African carnivores. Journal of Mammalogy 77:240-254.

Van Valkenburgh B. 2001. The dog-eat-dog world of carnivores: a review of past and present carnivore community dynamics. In: Stanford C, and Bunn HT, eds. Meat-Eating and Human Evolution. Oxford: Oxford University Press, 101-121.

Van Valkenburgh B. 2009. Costs of carnivory: tooth fracture in Pleistocene and Recent carnivorans. Biological Journal of the Linnean Society 96:68-81. 10.1111/j.10958312.2008.01108.x

Van Valkenburgh B, and Hertel F. 1993. Tough times at La Brea: tooth breakage in large carnivores of the late Pleistocene. Science 261:456-459.

Van Valkenburgh B, and Hertel F. 1998. The decline of North American predators during the late Pleistocene. In: Saunders JJ, Styles BW, and Baryshnikov GF, eds. Quaternary Paleozoology in the Northern Hemisphere. Springfield: Illinois State Museum, 357-374.

Van Valkenburgh B, Peterson RO, Smith DW, Stahler DR, and Vucetich JA. 2019. Tooth fracture frequency in gray wolves reflects prey availability. eLife 8:e48628. 10.7554/eLife.48628

Van Valkenburgh B, and Sacco T. 2002. Sexual dimorphism, social behavior, and intrasexual competition in large Pleistocene carnivorans. Journal of Vertebrate Paleontology 22:164169.

Van Valkenburgh B, Wang X, and Damuth J. 2004. Cope's rule, hypercarnivory, and extinction in North American canids. Science 306:101-104.

Vucetich JA, Peterson RO, and Waite TA. 2004. Raven scavenging favours group foraging in wolves. Animal Behaviour 67:1117-1126. https://doi.org/10.1016/j.anbehav.2003.06.018

Wang X. 1993. Transformation from plantigrady to digitigrady: functional morphology of locomotion in Hesperocyon (Canidae: Carnivora). American Museum Novitates 3069:123.

Wang X. 1994. Phylogenetic systematics of the Hesperocyoninae (Carnivora: Canidae). Bulletin of the American Museum of Natural History 221:1-207.

Wang X, Li Q, and Xie G. 2014. Earliest record of Sinicuon in Zanda Basin, southern Tibet and implications for hypercarnivores in cold environments. Quaternary International 355:310. 10.1016/j.quaint.2014.03.028

Wang X, Tedford RH, and Antón M. 2008. Dogs: Their Fossil Relatives \& Evolutionary History. New York: Columbia University Press.

Wang X, Tedford RH, and Taylor BE. 1999. Phylogenetic systematics of the Borophaginae (Carnivora: Canidae). Bulletin of the American Museum of Natural History 243:1-391.

Peer] reviewing PDF | (2020:05:48717:2:0:NEW 5 Aug 2020) 
687

688

689

690

691

692

693

694

695

696

697

698

699

700

701

702

703

704

705

706

707

708

709

710

711

712

713

714

715

716

717

718

719

720

721

722

723

724

Wang X, White SC, Balisi M, Biewer J, Sankey J, Garber D, and Tseng ZJ. 2018. First bonecracking dog coprolites provide new insight into bone consumption in Borophagus and their unique ecological niche. eLife 7:e34773. 10.7554/eLife.34773

Ware CS. 2005. Disease, skeletal injury and trauma as possible behavior modifiers in the fossil dire wolf Canis dirus (Canidae: Carnivora) from Rancho La Brea, California Ph.D. Union Institute \& University.

Werdelin L. 1989. Constraint and adaptation in the bone-cracking canid Osteoborus (Mammalia: Canidae). Paleobiology 15:387-401.

Wobeser G. 1992. Traumatic, degenerative, and developmental lesions in wolves and coyotes from Saskatchewan. Journal of Wildlife Diseases 28:268-275.

Zdansky O. 1924. Jungtertiäre carnivoren Chinas. Palaeontologia Sinica Series C 2:1-149.

Zhu R-x, Potts R, Xie F, Hoffman KA, Deng CL, Shi CD, Pan YX, Wang HQ, Shi RP, Wang YC, Shi GH, and Wu NQ. 2004. New evidence on the earliest human presence at high northern latitudes in northeast Asia. Nature 431:559-562.

\section{Captions of Figures}

Figure 1 Two dentaries of the same individual of Canis chihliensis. (A-D) left dentary (IVPP V17755.11); (E-H) right dentary (IVPP V17755.12). (A, E) occlusal views; (B, F) buccal views; $(\mathrm{C}, \mathrm{G})$ lingual views; (D, H) X-ray images. White arrows (labeled vab) indicate areas of increased vascularity of alveolar bone; red arrows (labeled pp) mark periodontal pocket, purple arrows (labeled fpp) indicate probable fistula from periodontal pocket, and blue arrows (labeled pi) mark periapical infections associated with exposed pulp chambers.

Figure 2 Frequencies of dental injury in the mandible of Rancho La Brea dire wolves, $\boldsymbol{C}$. dirus. (A) numbers of specimens of adult age bearing injuries similar to those in C. chihliensis (orange) compared with other dental injuries (gray). Most dental injuries in C. dirus involve abscesses and alveolar resorption stemming from infection. (B) categorization of dental injuries by tooth position. The $\mathrm{m} 1$ shows the highest frequency of infection or injury, followed by $\mathrm{p} 2$ and p4.

Figure 3 Tibias of the same individual of Canis chihliensis from SSMZ, Nihewan. (A-D) normal tibia of left side (IVPP V 18139.21). (E-H) pathologic tibia of right side (IVPP V 18139.20). (A, E) anterior views; (B, F) posterior views; (C, G) medial views; (D, H) lateral views. NF: nutrient foramen.

Figure 4 CT scan images of the pathologic right tibia of Canis chihliensis (V18139-20) from SSMZ, Nihewan. (A-B) anteroposterior longitudinal sections; (C-D) mediolateral longitudinal sections; (E) 3-D reconstruction of the pathologic tibia; (F-M) cross sections; (F-J) the upper part of the tibia; $(\mathrm{K})$ the upper and middle parts of the fracture; $(\mathrm{L})$ the middle and lower parts of the fracture; (M) lower part of the fracture, infection with subtle cortical loss. MC1-MC3, represent the medullar cavities of the three fractions of the fractured tibia; NP, nutrient foramen. 
725 Figure 5 Lower molars from SSMZ as compared to living hypercarnivorous taxa. Occlusal

726 views of lower molars, m1-3, of Canis chihliensis (A-C) from SSMZ in Nihewan, as compared

727 with those of C. lupus (D), Cuon alpinus (E) and Lycaon pictus (F). (A) right m1-3 (IVPP

728 V17755.6); (B) right m1-3 (IVPP V17755.4); (C) left (inverted) m1-2 (IVPP V17755.5); (D)

729 right m1-3 (IOZ no number, extant, China); (E) right m1-2 (IOZ 26747, extant, China); (F) right

730 m1-3 (T.M. No. 5560 and BPI/C 223, extant, South Africa). Modified from Tong et al. (2012). 


\section{Table 1 (on next page)}

Dimensional comparisons between the normal and pathologic tibiae of $C$. chihliensis (in: $\mathrm{mm})$.

Abbreviations: DAP: anteroposterior diameter; DT: transverse diameter. 
1

2 Table 1 Dimensional comparisons between the normal and pathologic tibiae of C. chihliensis (in:

$3 \mathrm{~mm}$ ). Abbreviations: DAP: anteroposterior diameter; DT: transverse diameter.

4

\begin{tabular}{l|c|c}
\hline Dimensions & $\begin{array}{c}\text { Normal } \\
\text { (left) tibia } \\
\text { (IVPP V } \\
18139.21)\end{array}$ & $\begin{array}{c}\text { Pathologic } \\
\text { (right) tibia } \\
\text { (IVPP V } \\
18139.20)\end{array}$ \\
\hline Maximum length & 181.6 & 166.5 \\
\hline Proximal DAP & 37.5 & $>32.2$ \\
\hline Proximal DT & 36.5 & 35.8 \\
\hline Distal DAP & 17.6 & $>17.3$ \\
\hline Distal DT & 24.1 & 25.7 \\
\hline $\begin{array}{l}\text { Shaft DAP at } \\
\text { nutrient foramen }\end{array}$ & 15.4 & 17.2 \\
\hline $\begin{array}{l}\text { Shaft DT at nutrient } \\
\text { foramen }\end{array}$ & 13.2 & 14.8 \\
$\begin{array}{l}\text { Shaft DAP at the } \\
\text { fracture }\end{array}$ & - & 25.5 \\
$\begin{array}{l}\text { Shaft DT at the } \\
\text { fracture }\end{array}$ & - & 29.2 \\
\hline
\end{tabular}

5

6 


\section{Figure 1}

Two dentaries of the same individual of Canis chihliensis

(A-D) left dentary (IVPP V17755.11); (E-H) right dentary (IVPP V17755.12). (A, E) occlusal views; (B, F) buccal views; (C, G) lingual views; (D, H) X-ray images. White arrows (labeled $\mathrm{vab}$ ) indicate areas of increased vascularity of alveolar bone; red arrows (labeled pp) mark periodontal pocket, purple arrows (labeled fpp) indicate probable fistula from periodontal pocket, and blue arrows (labeled pi) mark periapical infections associated with exposed pulp chambers.

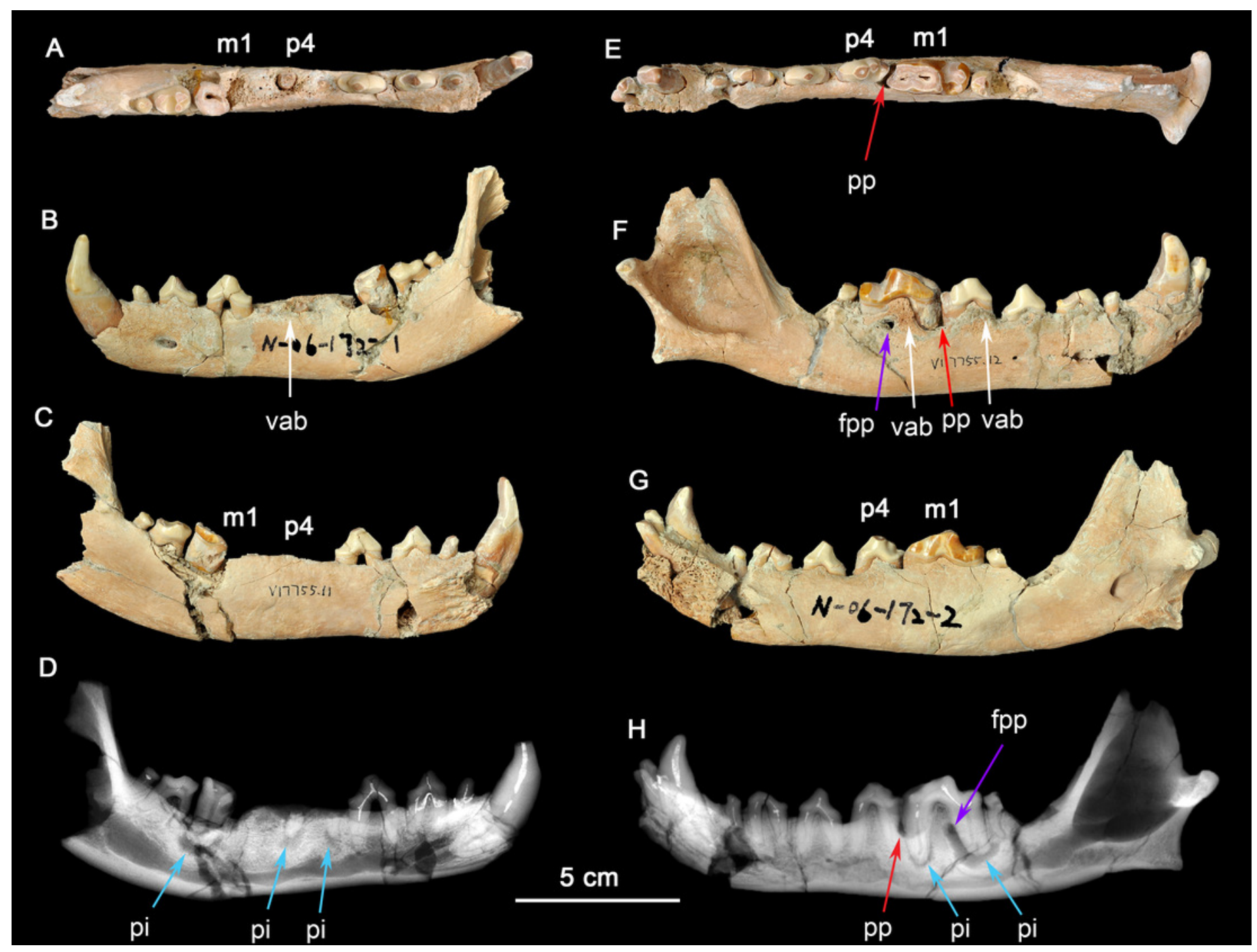




\section{Figure 2}

Frequencies of dental injury in the mandible of Rancho La Brea dire wolves, C. dirus.

(A) numbers of specimens of adult age bearing injuries similar to those in $C$. chihliensis

(orange) compared with other dental injuries (gray). Most dental injuries in C. dirus involve abscesses and alveolar resorption stemming from infection. (B) categorization of dental injuries by tooth position. The $\mathrm{m} 1$ shows the highest frequency of infection or injury, followed by $\mathrm{p} 2$ and $\mathrm{p} 4$. 


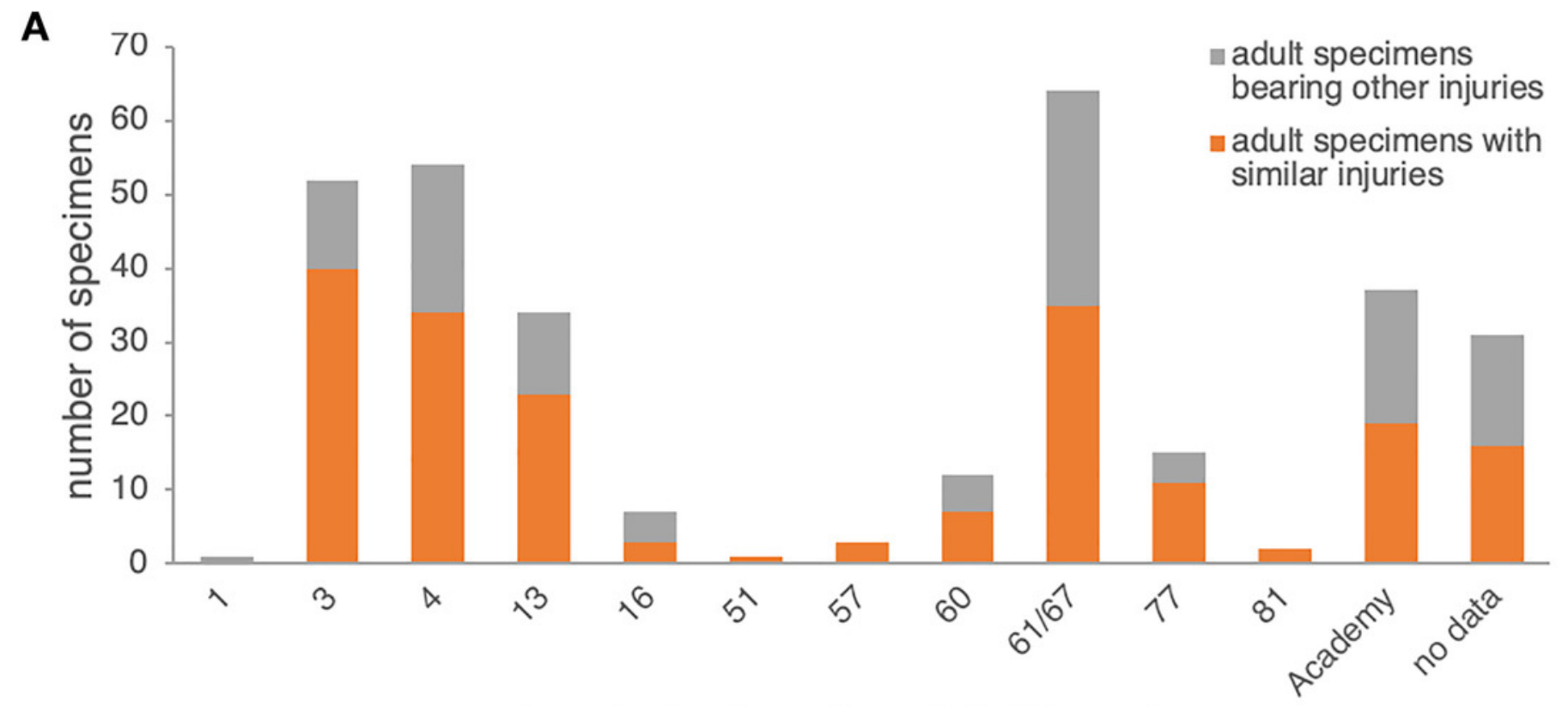

Rancho La Brea deposit ("pit") number

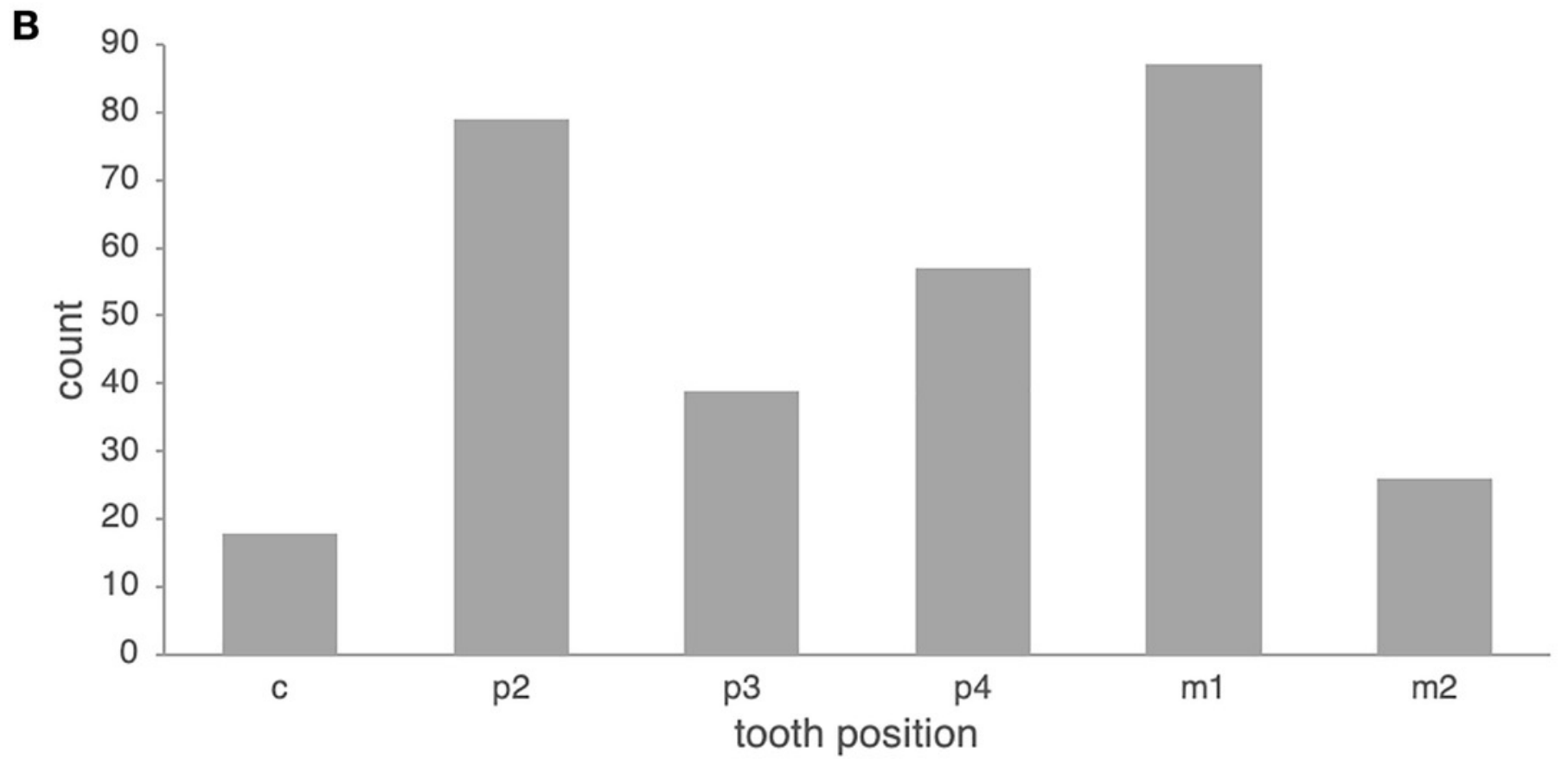




\section{Figure 3}

Tibias of the same individual of Canis chihliensis from SSMZ, Nihewan

(A-D) normal tibia of left side (IVPP V 18139.21). (E-H) pathologic tibia of right side (IVPP V 18139.20). (A, E) anterior views; $(B, F)$ posterior views; $(C, G)$ medial views; $(D, H)$ lateral views. NF: nutrient foramen.

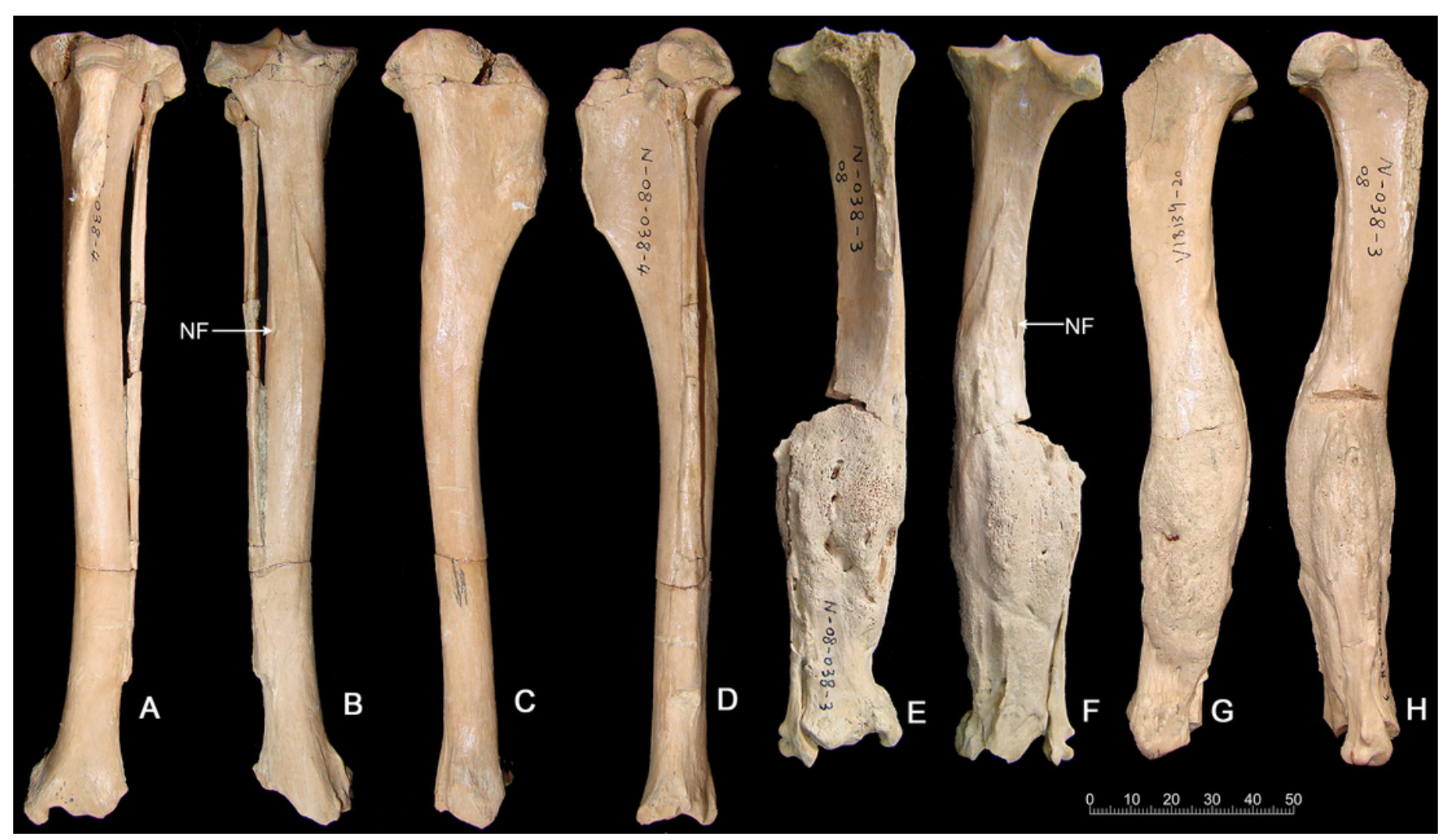




\section{Figure 4}

CT scan images of the pathologic right tibia of Canis chihliensis (V18139-20) from SSMZ, Nihewan

(A-B) anteroposterior longitudinal sections; (C-D) mediolateral longitudinal sections; (E) 3-D reconstruction of the pathologic tibia; (F-M) cross sections; (F-J) the upper part of the tibia; (K) the upper and middle parts of the fracture; (L) the middle and lower parts of the fracture; (M) lower part of the fracture, infection with subtle cortical loss. MC1-MC3, represent the medullar cavities of the three fractions of the fractured tibia; NP, nutrient foramen.

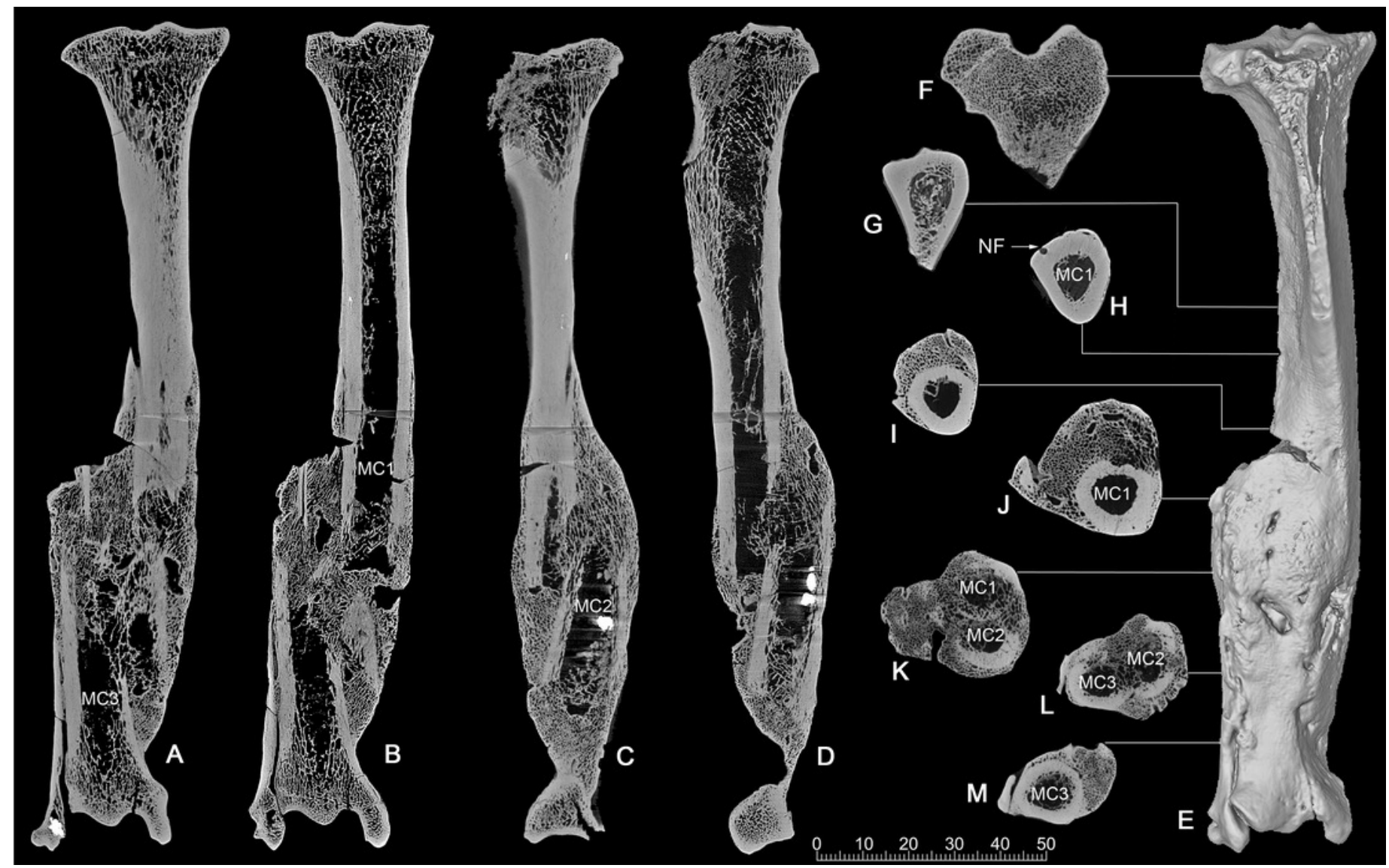




\section{Figure 5}

Lower molars from SSMZ as compared to living hypercarnivorous taxa.

Occlusal views of lower molars, m1-3, of Canis chihliensis (A-C) from SSMZ in Nihewan, as compared with those of C. lupus (D), Cuon alpinus (E) and Lycaon pictus (F). (A) right m1-3 (IVPP V17755.6); (B) right m1-3 (IVPP V17755.4); (C) left (inverted) m1-2 (IVPP V17755.5); (D) right m1-3 (IOZ no number, extant, China); (E) right m1-2 (IOZ 26747, extant, China); (F) right m1-3 (T.M. No. 5560 and BPI/C 223, extant, South Africa). Modified from Tong et al. (2012).
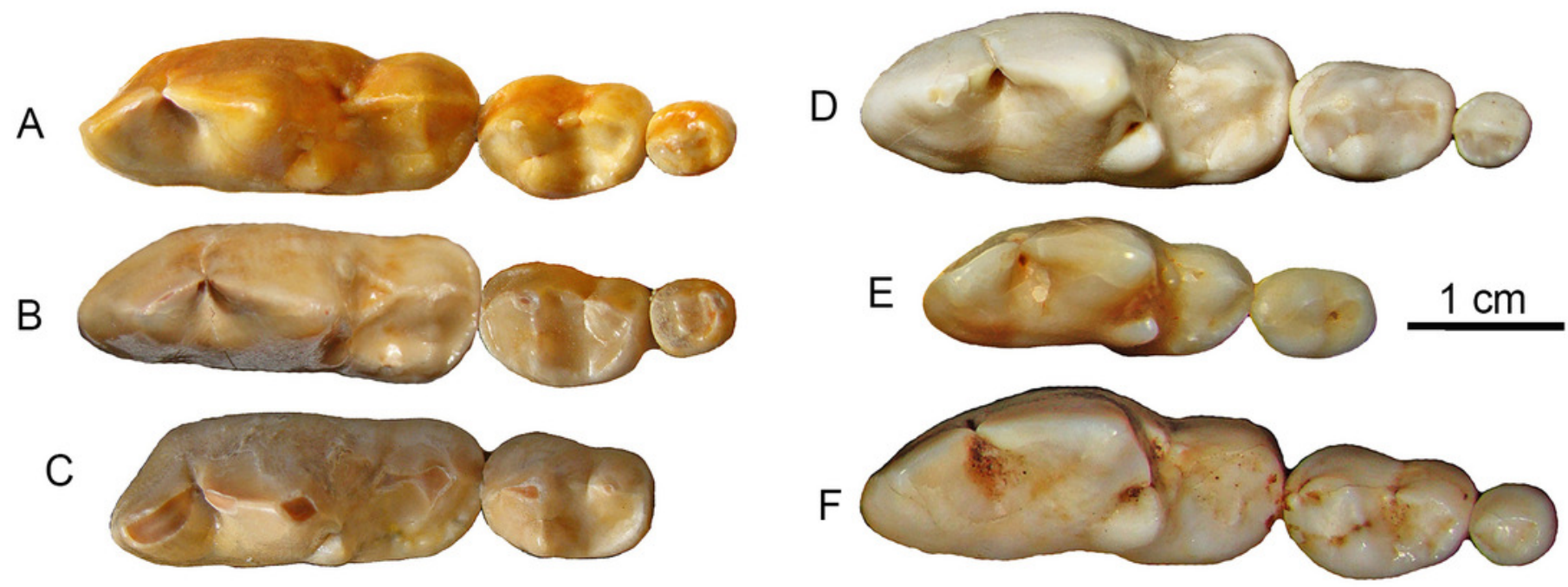